[141.78+7.038.6]:929 Lyotard J.-F.

7.038.6:821.111.09-2 Kane S.

https://doi.org/10.18485/asec_sacs.2021.9.ch4

\author{
Natalija Stevanović* \\ University of Niš, Serbia
}

\title{
LYOTARD'S NOTION OF UNPRESENTABLE THROUGH FRAGMENTED POSTMODERN SUBJECT IN SARAH KANE'S 4.48 PSYCHOSIS
}

\begin{abstract}
The central purpose of this paper is to analyze how the fragmented, postmodern subject is presented in Sarah Kane's play 4.48 Psychosis (1999). The key premise which guides this analysis is Jean-François Lyotard's (1984) notion of the postmodern "unpresentable", which serves to show how the representation of the postmodern subject in this play deviates from the norm of the pre-established rules in literature, which is, according to Lyotard, a hallmark of postmodernism. In the first part of this paper, Lyotard's definitions and explanations of postmodernism are provided, as a theoretical background of vital importance. The second part is dedicated to defining the fragmented postmodern subject, relying on Jolene Armstrong's Cruel Britannia (2015), Cathy Caruth's Unclaimed Experience (1996), and Brian McHale's Postmodernist Fiction (1994). The third, and the final, part is a close analysis of the play, with emphasis on particular scenes which portray the fragmented, postmodern subject. Hopefully, this small scale research shows how this play belongs in the postmodern tradition of representations of that which Lyotard sees as "unpresentable".
\end{abstract}

\section{Keywords}

fragmentation, Jean-François Lyotard, postmodernism, Sarah Kane, unpresentable.

\footnotetext{
*natalijast15@gmail.com
} 


\section{Introduction}

It is extremely difficult to place postmodernism within a certain timeframe, and to give particular dates as to when postmodernism rises to prominence. Another difficulty arises when trying to give definitions of postmodernism as a movement, not only a historical movement, but as a cultural as well. Much of it is influenced by the omnipresent elusiveness of the period that is vaguely taken to be the beginning of postmodernism, rather, the period after the Second World War. As is known, the post-war condition is that of confusion, loss of meaning, societal changes, all of which adds to the overall uncertainty in all spheres of life. This sort of condition requires understanding, considering the enormous impact, mostly negative, the Second World War, and its aftermath, has. Nevertheless, there is a rise in the interest of sciences and technology, which is seen as a favorable aspect. Therefore, Conseil des universités du Québec commissions a report on the influence of technology in exact sciences, and Jean-François Lyotard writes The Postmodern Condition (La Condition postmoderne, 1979). The importance of this report exceeds expectations, and establishes the term "postmodern" as something which serves the purpose of explaining the overall condition of the time. Having the immense impact of this report in mind, and also the myriad of ideas which Lyotard introduces in it, this paper opts to focus on one particular notion, which is that of the "unpresentable". This notion can be best explained when using a certain body of text, and the one chosen in this paper is the play 4.48 Psychosis (2000) by Sarah Kane, as one of the texts where there is a fragmented, postmodern subject, displaying some of the characteristics of the unpresentable as Lyotard sees it.

With this in mind, the first part of this paper is dedicated to explaining postmodernism rather than defining it (as it is almost impossible to do so) with the focus on Lyotard's understanding of it. The second part of this paper is dedicated to defining the postmodern, fragmented subject. This part's main focus is on introducing the concept of a postmodern subject, and explaining why it displays fragmentation as a pervasive state. The third and the final part is dedicated to the close analysis of the play 4.48 Psychosis by Sarah Kane, in the light of its connection to Lyotard's concept of the "unpresentable".

\section{Jean-François Lyotard's Notion of Postmodernism}

To this day, there has not been a clear-cut definition of postmodernism, as it eludes strict definitions as much as it eludes a precise date on which it became a widely used term. According to Jean-François Lyotard, it coincides with the completion of restoration in Europe, which is roughly the period after the 1950s, in the years following the end of the Second World War (Lyotard 1984: 1). This 
period is marked by the changes in technology and means of communication, which all lead to the creation of a post-industrial, computerized, mass-media society. Lyotard claims that in postmodernism we see the spreading of capitalism, and its control and guidance over the acquisition of new and already existing knowledge. "Knowledge is and will be produced in order to be sold, it is and will be consumed on order to be valorized in a new production: in both cases, the goal is exchange" (Lyotard 1984: 4). He sees two types of knowledge which can be exchanged; scientific and narrative knowledge (Lyotard: 1984: 7). Scientific knowledge is self-explanatory, however, narratives are stories which belong to every single community, and the purpose of those stories is to explain the past, the present, and the future (Maširević 2011: 93). Narrative knowledge is therefore important, as it is in the very core of the human experience and community. Narratives tell the story of the people and their world. There are two grand narratives, or metanarratives, of the past - the narrative of emancipation (where the hero were the people), and the narrative of speculation (centering on the spirit of the individual). (Maširević 2011: 95) However, according to Lyotard, postmodernism is marked by an "incredulity towards metanarratives," which is caused by the progress in sciences (Lyotard 1984: xxiv). Their purpose in the past was to: "[...] legitimize science in two ways: as an instrument of social liberation, and as an accumulation of knowledge as a good in its own right" (Petrović 2004: 301). But, as science develops, so do the possibilities an individual has, and the overall understanding of the world, all of which makes people question those grand narratives, as they seem to no longer hold as much value as they used to. Lyotard's plea is to reject those grand narratives of the Western culture since they do not have enough credibility to: "[...] sum up the ethos of postmodernism, with its disdain for authority in all its many guises" (Stuart [ed]: 2001: 3). Instead of those grand narratives, he suggests turning to other types of narratives which can be found in different discourses and which are followed by different rules (Maširević 2011: 94).

Those different types of discourses are seen as language games, in place of the grand narratives, and they are small, and discrete from each other and they all obey their own rules, and they are fragmented. Language games are seen as: "[...] the minimum relation required for society to exist" (Lyotard 1984: 15). "As Ludwig Wittgenstein has it, 'language games are not simply exchanges of verbal behavior', they are indissolubly linked to 'forms of life" (Stuart [ed]: 2001: 75). Fragmentation comes forth as the people abandon unique metanarratives, and turn to multiple language games which offer opportunities for the development of their identities (Maširević 2011: 97). Lyotard sees this fragmentation as necessary to fight the forces of capitalism, and suggests their further fragmentation. Identities, which no longer follow the grand narratives, also become dispersed and fragmented, with different perspectives, attitudes towards the changes in their society. All of this introduces new ideas, which 
are difficult to represent. Drawing on the Kantian notion of sublime, Lyotard explains that it is a sentiment which takes place: "when the imagination fails to present an object which might, if only in principle, come to match a concept" (Lyotard: 1984: 78). Basically, now we have ideas whose presentation is simply impossible, and they are the unpresentable. In postmodernism, we have an omnipresent endeavor to find the means to present them. These kinds of changes influence not only the transmission of knowledge, but knowledge itself. Lyotard emphasizes that the postmodern is that which: "[...] puts forward the unpresentable in presentation itself [...] that which searches for new presentations, not in order to enjoy them, but in order to impart a stronger sense of the unpresentable" (Ibid. 81). Even though this paper by Lyotard was originally intended as a scientific paper, its importance can be felt in literature as well. Particularly in that literature which is seen as postmodern. In light of this, the next part of this paper is dedicated to explaining the notion of the fragmented, postmodern subject, which is, even though deemed unpresentable, rather marvelously displayed in 4.48 Psychosis by Sarah Kane.

\section{Fragmented Postmodern Subject}

In postmodern times there is no confidence in our ability to know the truth. There is no metanarrative which serves to define and give a context to everything. Change is fundamental, and changes come often and do not always form a coherent pattern. There is no me that is identifiable throughout my life, because identity is constantly changing and is defined by various relations we have with others. Postmodernism, with its uncertainties, with its "splintering of culture" (Lyotard 1984: 72), poses an ongoing crisis for an individual. Jolene Armstrong observes these changes in Britain, and, as well as Lyotard, sees postmodernism as an expression of the late capitalist/post-industrial culture, but its underside is "blood, torture, death, and terror" (Armstrong 2015: 13). The changes that she observes are the changes which appear as an answer to the Thatcher revolution. As a result of the interest in the art of subversion due to the new changes by means of shock, In-Yer-Face theatre appears, as a "general backlash against cultural norms" (Ibid.). There is a need to represent this new sensibility. With this idea comes the appearance of the new, postmodern subject, which lives in the chaos of the changes introduced in the society. Sarah Kane portrays this subject, in the tradition of the postmodern In-Yer-Face theatre, by using experience, sensation, experimenting, shock tactics, and provocation, to get under the spectators' skin and in their faces. Essentially, postmodernism with its "splintering of culture", poses a crisis for an individual and in Kane's plays, her characters deal with postmodernist concerns, which are shown as a hyper-awareness, anxiety, and uncertainty with living in an unpredictable world (Armstrong 2015: 22). 
Lyotard argues that in postmodern literature the characters and events "always come too late"; their realization always begins too soon" (Lyotard 1984: 81) - the notion of beginning too soon, of experiencing something prematurely is at the very root of trauma, which is, as Cathy Caruth explains "an event that is experienced too soon, too unexpectedly, to be fully known and is therefore not available to consciousness until it imposes itself again, in the nightmares and repetitive actions of the survivor" (Caruth 1996: 4). All of this describes the overall condition in which postmodern individuals live - trauma, uncertainty, fear, which adds to their further fragmentation. Having in mind both Lyotard's theory of the postmodern condition as premature, even sudden, and Caruth's formulation of trauma as also a premature and violently sudden action, we have a postmodern fragmented subject, traumatized by the new condition which came far too soon. In 4.48 Psychosis, the individual is fragmented, suffering from a traumatic slip with her/his own repetitive memories and postmodern experiences, going through the crisis of memory in a society which has gone through a traumatic separation of subjectivity, knowledge, and at the same time, existence and being (Armstrong 2015: 24). This state of mind can only be represented in the form of a mindscape, a place between a dream and waking life, sanity and insanity, reality and fantasy - fragmentation (Strnadova 2008: 30). Through the words in this play, we can see that there is no stable world behind the consciousness, but only a flux of discourse in which fragments of different, incompatible realities "flicker into existence and out of existence again, which is postmodernist fiction in short" (McHale 2004: 234). The "unpresentable" that Lyotard sees is the very essence and subject matter of Kane's oeuvre (Armstrong 2015: 25). However, there has to be a particular space for placing such an unpresentable world. According to Brian McHale, there is a space called "heterotopia", a term which he borrows from Michael Foucault, and which is a dimension where things which are inappropriate are linked together, where there is a disorder of fragments of multiple possible worlds. "[...] Heterotopias are disturbing, probably because they secretly undermine language, because they make it impossible to name this and that, because they destroy "syntax" in advance, and not only the syntax with which we construct sentences but also that less apparent syntax which causes words and things (next to and also opposite to one another) to "hold together" (2004: 44). Amidst this destruction of the known rules, a space is created which a postmodern, fragmented subject can claim as her/his own. The inner fragmentation matches the fragmentation in the outside world, and together they contribute to the creation of a whole new, postmodern space. 


\section{4.48 Psychosis}

Clearly, a wide range of ontological themes or attitudes is available to postmodernist writers, and it is important to specify which writers display which attitudes. But it is equally important to recognize that these attitudes, whatever they may be, come to our attention only through the foregrounding of ontological concerns which is common to all postmodernist writers, and that to accomplish this foregrounding all postmodernists draw on the same repertoire of strategies. (McHale 2004: 27)

What makes Sarah Kane's plays postmodern, including 4.48 Psychosis, is her tendency to shape her plays around ontological questions of existence, which Brian McHale enumerates, such as: "Which world is this? What is to be done in it? Which of my selves is to do it?" (Armstrong 2015: 22). Her ontological concerns are represented as, for example, "existential anxiety over death, suffering, responsibility, and alienation" (Ibid.). Jolene Armstrong explains that Kane's plays are postmodern in that they portray "deconstruction of the concept of unified identity and the delegitimation of prevalent and conventional concepts" (2015: 22). Basically, there is no unified identity, rather fragments or the remnants of a once complete person, who starts posing ontological questions in order to find some meaning and the place to belong to. However, the places are fragmented as well. "Kane's plays question political and ethical norms, presenting themes that repeatedly surface like a recurring nightmare: the destabilizing nature of transgressive sexuality, the social role of violence, the ethics of suicide, the increasing frequency of repetitive memory as postmodern experience, and its attendant results of trauma and social alienation; within a paradigm of postmodern trauma" (Armstrong 2015: 21). In 4.48 Psychosis, individuals are fragmented, going through the crisis of memory in a society which has gone through a traumatic separation of subjectivity, knowledge, and at the same time, existence and being (Armstrong 2015: 24). This crisis can be seen in the memory loops in the character; the character who is suffering from a traumatic split with her/his own memories and experiences, who must reconcile the traumatic experiences and effects of them, as they are coming to terms with the personal violence and alienation from the society (Armstrong 2015: 24). :This state of mind can only be represented in the form of a mindscape, a place between a dream and waking life, sanity and insanity, reality and fantasy - that is precisely how this play deals with the existential questions and the character's own fragmentation (Strnadova 2008: 30).

Postmodernism, with its uncertainties, with its "splintering of culture" (Lyotard 1982: 72), poses an omnipresent crisis for an individual. In her plays, Kane connects the postmodern condition and presents it as a traumatic experience, the one in which her characters can find no closure, in which they live in a constant 
state of trauma (Armstrong 2015: 25). In Kane's plays, her characters deal with postmodernist concerns, which are shown as a hyper-awareness, anxiety, and uncertainty with living in an unpredictable world (Armstrong 2015: 22). In 4.48 Psychosis, Kane manages to portray this loss of self by abandoning concrete character identities, and adding to the notion of the death of an individual within a dying society (Armstrong 2015: 17). The discourse of 4.48 Psychosis moves us to a "mindscape", where it deals with existential questions (Klara 2008: 30). 4.48 Psychosis as a work of art is a theatrical enactment of depression and suicide within which is the expression of the fragmented postmodern subject and the impossibility of presenting an individual as a unified whole, as a cohesive logical unit, emphasizing once again Lyotard's notion of the unpresentable, or the impossibility of representation (Armstrong 2015: 177).

This play can be best described as the "complicated poetry of a fragmented consciousness in its final moments" (Armstrong 2015: 193). It does not precisely specify the number of characters, their gender, age; we are rather given fragments of a mind tormented by an illness which takes control of her/his life and renders her/him unable to have a normal life, showing inability to be a cohesive, logical unit, an individual (Armstrong 2015: 179). Unlike in her previous plays, Kane does not portray any graphic violence which made her name as a playwright; rather, the language is violent, language which portrays the inhumanity of the medical system, the unwillingness to help a person in need.

This recurrent linking of mental illness, the fractures of late capitalist society and the linguistic experiments of contemporary writing is not accidental. Temporal disorder, involuntary impersonation of other voices (or pastiche), fragmentation, looseness of association, paranoia and the creation of vicious circles are symptoms of the language disorders of schizophrenia as well as features of postmodernist fiction. (Stuart [ed]: 2001: 133)

The choice of a character who suffers from a mental illness is not incidental. Besides the fact that a mentally ill person serves to effectively portray the fragmentation within, it also portrays the fragmentation outside, showing how the world cannot offer a place for the human beings who do not fit into the status quo; rather, it institutionally murders them (Armstrong 2015: 179). Another notion which goes hand in hand with fragmentation, is the sense of alienation. People do not communicate, but rather live in their own world, unable to understand the needs of each other. In 4.48 Psychosis, we have two sentences which perfectly summarize this sentiment.

[Psychologist]. You don't need a friend you need a doctor.

[Patient]. You are so wrong. (Kane 2000: 35) 
This person, this fragmented consciousness, suffers from depression, and is unable to help herself/himself. Rather, she/he is seeking understanding in the persona of a psychologist who seems to be the only one to understand in the world of the doctors who offer "chemical cures for congenital anguish" (Kane 2000: 6). However, even that psychologist chooses to not get involved. Even though they talk and exchange their thoughts on life, there is still a barrier which the psychiatrist put there in order to prevent the maddening influence of fragmentation from the speaker. The only solace the speaker finds is at 4.48, when sanity visits and she/he is in her "right mind"; after it passes: "I shall be gone again, a fragmented puppet, a grotesque fool" (Kane 2000: 21). The speaker is a dis-unified subject, unable to connect the pieces of the mind, controlled as a puppet by the forces of psychiatry (Armstrong 2015: 189). She/he loses the sense of the self, of the individuality, and disintegrates. Suicide is seen as a way out, as an utmost fragmentation; as salvation even.

Kane chooses a mentally ill person, in order to show the postmodern fractured self (Armstrong 2015: 198). The only way out from this disintegration is love, which is seen as "the vital need" for which she/he would die, to be loved (Kane 2000: 31). But this vital need, or rather, the lack of it, further tears apart the already fragmented personality. Nearing the end of the play, we can literally see the fragmentation of a postmodern subject on page. Random strings of sentences, followed by the request to "watch" and "open the curtains", show a plea of a fragmented subject who is asking someone to see, to help, to listen. This seems to be an idea which cannot be presented, however, in the postmodern blurring of the boundaries between what is appropriate in art, in this fragmentation, we have a situation that when worlds and identity or selves are confronted by various stimuli, or violated, the world becomes an inner landscape of shifting centers - the unpresentable (Armstrong 2015: 208). The visual and verbal fragmentation on paper implies that this consciousness committed suicide. Death is, therefore, another way to further fragment a personality, and another ontological boundary that we are all bound to experience sooner or later, but, in postmodernism, unlike other periods, death is put forward and represented (McHale 2004: 231).

Even though Kane chooses a stereotypical character, a patient in a mental institution, the psychological reality of the individual self, the nightmarish visions, the emptiness, the frustration, the despair, and the loss of subjectivity in her character add to the play's raw emotional authenticity, and allow us to connect to the character through postmodern formal devices and hints of deconstruction (Mangold 2007: 17). Her play portrays an individual who is not only fragmented, but also, in the spirit of postmodernism, is unwilling to even attempt to reassemble the fractured pieces (Armstrong 2015: 181). It portrays the postmodern condition of the lack of a: "[...] stable world behind 
this consciousness, but only a flux of discourse in which fragments of different, incompatible realities flicker into existence and out of existence again" (McHale 2004: 234). And this flickering, this fragmentation and unwillingness to change it, this incompatibility and uncertainty, is precisely the "unpresentable" that Lyotard emphasized as the postmodern.

\section{Conclusion}

Thanks to Jean-François Lyotard, quite an elusive period is placed within a framework, albeit flexible, in order to help understand a mindset of the artists and scientists of the time alike, as well as ordinary people, who live in the aftermath of the Second World War. Considering the fact that it gives a meaning of a kind to the omnipresent meaninglessness of the post-war world, its effects are felt even today. There is a reluctance on behalf of many authors and theoreticians to accept postmodernism as a valid period when it comes to both culture and literature, mostly because of its lack of established rules, abandonment of the narratives which used to serve people for quite a long time, and confusion which permeates all the aspects of the postmodern world. Yet, when all is taken into account, the importance of postmodernism cannot be undermined, and its existence cannot be denied.

First and foremost, the importance is obvious in the fact that dubbing the period after 1950s as the postmodern, understanding is provided for the period represented by the general confusion and fragmentation. It allows for the new language games to come into existence, and it abandons the grand narratives which are seen as an oppressive force in their attempt to shape societies with their strict guidelines. It gives voice to the unpresentable and the unpresented, to those aspects of the world which were, until then, deemed inappropriate to represent. It encourages the suppressed aspects of societies to come forth and further explain the overall condition which is known as the postmodern condition. And it also allows for the space in which Sarah Kane's play 4.48 Psychosis can be analyzed, as a perfect example of the portrayal of a fragmented, postmodern subject.

\section{WORKS CITED}

Armstrong, Jolene. Cruel Britannia: Sarah Kane's Postmodern Traumatics. Bern: P. Lang, 2015.

Caruth, Cathy. Unclaimed Experience: Trauma, Narrative, and History. Baltimore: The Johns Hopkins University Press, 1996.

Kane, Sarah. 4.48 Psychosis. Methuen, 2000. 
Lyotard, Jean- François. The Postmodern Condition: A Report on Knowledge. Minneapolis: University of Minnesota Press, 1984.

Mangold, Alex. "The Empty 'I' - Echoes of Subjectivity in Sarah Kane's Crave". Consciousness, Theatre, Literature and the Arts, (2007), 116-125.

Maširević, Ljubomir. Postmoderna teorija i film na primeru kinematografije Kventina Tarantina. Beograd: Čikoja štampa, 2011.

McHale, Brian. Postmodernist Fiction. London ; New York : Routledge : Taylor and Francis, 2004.

Petrović, Lena. Literature, Culture, Identity: Introducing XX Century Literary Theory. Niš: DIGP "PROSVETA", 2004.

Sim, Stuart (ed.). The Routledge Companion to Postmodernism. London; New York: Routledge, 2001.

Strnadová, Klára. Violence and Formal Challenge in the Plays of Sarah Kane and Martin Crimp. PhD thesis, 2008. 